\title{
Análisis de necesidades en familias monoparentales con jefatura femenina usuarias de servicios sociales de atención primaria en España
}

\author{
Celia María Fernández-Martínez
}

Graduada en Trabajo Social. Licenciada en Sociología

Universidad de Murcia. Murcia, España

http:/ / orcid.org/0000-0001-8895-2601 • celia.fernandez@molinadesegura.es

Manuela Avilés-Hernández

Diplomada en Trabajo Social. Doctora en Sociología

Universidad de Murcia. Murcia, España

http:// orcid.org/0000-0002-8673-0690 • manoliaviles@um.es

\section{Resumen}

Esta investigación tiene como propósito identificar las necesidades que presentan las familias monoparentales con jefatura femenina atendidas por los Servicios Sociales de Atención Primaria en España. También se busca averiguar qué recursos y apoyos utilizan para afrontar su situación de necesidad. Se ha optado por un estudio exploratorio y sincrónico. Las unidades de análisis son las jefas de una familia monoparental que han acudido a servicios sociales de atención primaria. Estas mujeres tienen a su cargo hijos menores de 18 años o mayores de esa edad, pero incapacitados judicialmente y/o en situación de dependencia. En términos metodológicos, el estudio es cualitativo y de ámbito local. Se basa en una entrevista semiestructurada en profundidad a 10 mujeres que responden al perfil de la unidad de análisis. Los resultados indican que las principales necesidades con las que se encuentran son, por este orden: económicas, laborales, de conciliación y ajuste emocional. El apoyo que reciben por parte de los sistemas de protección social es puntual e insuficiente, aunque les permite aliviar sus circunstancias en el momento concreto en el que lo reciben. El apoyo informal, en especial de sus familiares más próximos, es el recurso que está dando principal respuesta a sus necesidades. El estudio muestra la necesidad de diseñar una política familiar de carácter integral, adaptada a las necesidades específicas de estas formas de familia. En el trabajo se presentan diversas propuestas de intervención, desde la óptica de las mujeres entrevistadas, protagonistas en primera persona de las necesidades diagnosticadas.

Palabras clave: Familias Monoparentales; Jefatura Femenina; Feminización de la Pobreza; Necesidades Sentidas y Expresadas; Servicios Sociales.

Recibido: 24/01/2020 | Aprobado: 30/04/2020

(i)(2) Esta obra está bajo una Licencia Creative Commons Atribución-NoComercial-CompartirIgual 4.0 Internacional.

Procedencia del artículo: Este artículo se deriva del proyecto de investigación Análisis de necesidades de los núcleos familiares monoparentales usuarios de servicios sociales de atención primaria, desarrollado por las autoras en la Facultad de Trabajo Social de la Universidad de Murcia (España).

¿Cómo citar este artículo? / How to quote this article?

Fernández-Martínez, C.M., y Avilés-Hernández, M. (2020). Análisis de necesidades en familias monoparentales con jefatura femenina usuarias de servicios sociales de atención primaria en España. Prospectiva. Revista de Trabajo Social e intervención social, (30), 145-173. doi: 10.25100/ prts.v0i30.8855. 
Fernández-Martínez y Avilés-Hernández

\title{
Analysis of Needs in Female-Headed Single Parent Families Who are Users of Primary Care Social Services in Spain
}

\begin{abstract}
The purpose of this research is to identify the needs of female-headed single parent families who are users of Primary Care Social Services in Spain, as well as, the resources and support these women use to face their situation. The study is of an exploratory and synchronic nature. The units of analysis are the single mothers who are users of Primary Care Social Services and have children under the age of 18 or ones who are older but judicially incapacitated and/or in a situation of dependency. In methodological terms, the study is qualitative and local. A semi-structured in-depth interview was conducted with 10 women, who corresponded to the profile. The results indicate that the main needs they face are, in this order: economic, employment, conciliation and emotional adjustment. The support they receive from social protection systems is specific and insufficient, although it allows them to alleviate their circumstances at the specific moment in which they receive it. Informal support, especially from close relatives, is the resource that is providing the main response to their needs. The study shows the necessity of designing an integral family policy, adapted to the specific needs of these types of family. The paper presents various proposals for intervention, from the point of view of the interviewed women, protagonists of the diagnosed needs.

Keywords: Single Parent Families; Female-Headed Households; Feminization of Poverty; Felt and Expressed Needs; Social Services.

Sumario: 1. Introducción, 2. Las familias monoparentales con jefatura femenina en España: definición y alcance, 3. Los Servicios Sociales de Atención Primaria en España, 4. Metodología, 5. Hallazgos, 5.1 Necesidades sentidas, 5.2 Gestión de necesidades, 6. Conclusiones, 7. Referencias bibliográficas.
\end{abstract}




\section{Introducción}

...defender que el trabajo social no es solo un proceso educativo para la adaptación de la gente en la sociedad en que vive, sino, además, y simultáneamente, un proceso de investigación permanente para conseguir avances y reformas sociales para el progreso de la sociedad.

Mary E. Richmond (1995).

En las últimas décadas, la familia española ha experimentado profundas transformaciones en lo que se refiere a su forma, tamaño y organización. Estas son consecuencia de los progresos y cambios vividos por la propia sociedad. Nos referimos, entre otros, a los cambios legislativos (en materia de filiación, divorcio, matrimonio, etc.), los avances médicos (control de natalidad, incremento de la esperanza de vida, etc.), la transformación del estatus de las mujeres y su emancipación (mayor nivel de estudios, incorporación al mercado laboral, relaciones más simétricas con respecto a los hombres, etc.), y el cambio de valores y normas sociales (individualización, mayor laicismo, necesidad de autorrealización personal, etc.).

La institución familiar se ha adaptado a la nueva realidad social, desde el modelo de familia tradicional hacia una mayor diversidad: parejas que conviven juntas sin estar casadas, familias monoparentales, familias ensambladas o reconstituidas, parejas homosexuales, etc. (Ruiz, 2004). Estas nuevas familias no son exclusivas de nuestro tiempo, pues han existido a lo largo de la historia. Sin embargo, nunca han tenido la relevancia social que tienen ahora. Por eso, es necesario desarrollar actuaciones que permitan conocer las necesidades específicas que presentan, con el fin de planificar acciones de intervención social eficaces y realistas.

En este estudio, la atención se centra en las familias monoparentales encabezadas por una mujer que acuden a los Servicios Sociales de Atención Primaria en España. La finalidad es conocer las dificultades y necesidades que tienen a distintos niveles, narradas por sus protagonistas. El trabajo se inicia con el marco teórico, donde se aborda el fenómeno de la monoparentalidad en España y el papel que desempeñan los Servicios Sociales de Atención Primaria en pro de resolver o, al menos, minimizar las situaciones de necesidad. A continuación, se explica la metodología que se ha seguido para la consecución de los objetivos propuestos. Por último, se exponen los resultados, cuyo análisis derivará en las conclusiones.

\section{Las familias monoparentales con jefatura femenina en España: definición y alcance}

La monoparentalidad ha estado presente a lo largo de la historia en todas las sociedades. Sin embargo, es en el momento actual cuando ha adquirido mayor relevancia, 
por su incremento y la heterogeneidad de situaciones que representa (Avilés, 2013). El concepto, en su sentido más amplio, se refiere a la convivencia de un progenitor con sus hijos. De acuerdo con los distintos análisis conceptuales que se han hecho (Almeda et al., 2010; Avilés, 2015; Barrón, 2002; Rodríguez y Luengo, 2003, 2011), los elementos clave en la definición son dos: la presencia en el mismo hogar de un progenitor y uno o varios de sus hijos, y la dependencia de esos hijos con respecto al progenitor con el que conviven.

La dependencia de los hijos es uno de los criterios fundamentales para considerar que una familia es monoparental. En este punto, la controversia aparece al definir qué se entiende por hijo dependiente. Hay quien considera que la simple convivencia en el mismo hogar ya implica, de por sí, una dependencia del hijo con respecto a su padre o madre. Otros cuestionan esta generalidad y prefieren incorporar elementos de precisión. El más utilizado es la edad de los hijos. Sobre ella existen diversas consideraciones, desde los 16 años, momento en el que la ley permite la emancipación del menor en España, hasta los 25, que es la edad límite para ser beneficiario de diversas prestaciones. En ocasiones, la referencia se fija en los 18 años, que es cuando se alcanza la mayoría de edad en países como España. Otro aspecto que se utiliza para determinar el grado de dependencia de los hijos es su estado civil. Con base en él, se consideran dependientes todos aquellos hijos solteros que conviven junto al progenitor. Elementos menos utilizados en las definiciones de monoparentalidad son la incapacidad física y/o psíquica del hijo o su dependencia económica con respecto al progenitor. En este último caso, se suele plantear que el hijo será dependiente cuando perciba unos ingresos por rendimiento de trabajo inferiores a una determinada cantidad.

Las causas que originan la monoparentalidad son diversas, si bien la literatura ha identificado cuatro (Iglesias de Ussel, 1988, 1998):

1. Viudedad, ha sido durante gran parte de la historia la causa principal de que una familia se convirtiera en monoparental. Recientemente, está cediendo el protagonismo a las rupturas conyugales, más concretamente al divorcio.

2. Ruptura conyugal, donde se incluiría el divorcio, la separación legal o de hecho, y el abandono del núcleo familiar por parte de uno de los miembros de la pareja.

3. Maternidad en solitario, que puede ser elegida, como en los casos de adopción y reproducción asistida, o sobrevenida, como sucede cuando una mujer queda embarazada y la pareja se desentiende del cuidado del hijo.

4. Causas sociales que obligan a la pareja a vivir separada. Algunas son la encarcelación, emigración y hospitalización prolongada de uno de los miembros de la pareja.

Si nos centramos en el caso concreto de España, los datos oficiales más recientes señalan que, en 2019, existían 1.887.500 hogares monoparentales. Este dato representaba el 10,1\% del total (véase Tabla 1). Se trata de la cuarta forma de convivencia más extendida, 
Fernández-Martínez y Avilés-Hernández

por detrás de los hogares biparentales con hijos (33,5\%), los hogares de una sola persona $(25,7 \%)$ y los hogares de una pareja sin hijos convivientes $(21,1 \%)$.

Tabla 1. Número de hogares en España según el tipo, 2019

\begin{tabular}{lcc}
\hline \multicolumn{1}{c}{ Tipo de hogar } & $\begin{array}{c}\text { Valor Absoluto } \\
\text { (en miles) }\end{array}$ & \% \\
\hline Hogar unipersonal & $4.793,7$ & 25,7 \\
Hogar monoparental (un adulto con hijos) & $1.887,5$ & 10,1 \\
Pareja sin hijos que convivan en el hogar & $3.937,2$ & 21,1 \\
Pareja con hijos que convivan en el hogar & $6.219,0$ & 33,5 \\
• Pareja con un hijo que conviva en el hogar & $2.916,8$ & 15,7 \\
• Pareja con dos hijos que convivan en el hogar & $2.751,8$ & 14,8 \\
• Pareja con tres o más hijos que convivan en el hogar & 550,4 & 3,0 \\
Núcleo familiar con otras personas que no forman núcleo familiar & 806,4 & 4,3 \\
Personas que no forman ningún núcleo familiar entre sí & 558,2 & 3,0 \\
Dos o más núcleos familiares & 423,6 & 2,3 \\
Total & $\mathbf{1 8 . 6 2 5 , 7}$ & $\mathbf{1 0 0 , 0}$ \\
\hline
\end{tabular}

Fuente: Instituto Nacional de Estadística de España-INE. (2020).

Atendiendo al número de hijos que viven en el hogar monoparental, los datos de esta encuesta indican que en el 68,6\% de los casos hay uno, en el 26,3\% dos, y en el 5,1\% tres o más. Vemos que predominan las situaciones en las que el progenitor vive únicamente con uno de sus hijos, creando estructuras de tamaño reducido. Esto no sucede en el caso de los hogares biparentales con hijos. Si se revisan los datos de la tabla, se aprecia que la cantidad de hogares en los que la pareja convive con un hijo es parecida a la de aquellos en los que convive con dos (15,7\% y 14,8\%, respectivamente).

Al igual que en otros países, la mayoría de hogares monoparentales estaban, en 2019, bajo la responsabilidad de la madre, en concreto el $81,1 \%$. Las series históricas que ofrece el Instituto de la Mujer de España muestran que, la proporción de familias monoparentales con jefatura femenina siempre se ha situado por encima del $80 \%$. En algún momento, como en el año 2002, estuvo, incluso, por encima del 90\%. Esto permite afirmar que se trata de un fenómeno claramente feminizado.

La presencia de un único progenitor en el hogar, en especial si es la madre, implica una serie de dificultades y necesidades. Estas giran en torno a dos áreas: socioeconómica y psicosocial. 


\section{-Área socioeconómica}

Con respecto a la primera, las familias monoparentales tienen un nivel de vida más bajo que el resto, pues la crianza del hijo conlleva una serie de gastos fijos que son asumidos por un único progenitor. Es decir, estas familias cuentan con un solo ingreso, a diferencia de lo que ocurre en las biparentales, donde ambos progenitores pueden estar trabajando. Sin embargo, los gastos que tienen son similares a los de cualquier tipo de familia con hijos. Esto hace que presenten un mayor riesgo de pobreza que las familias con dos proveedores. A ello se suma que la pensión de alimentos que pagan los padres separados o divorciados sin la custodia, suele ser de escasa cuantía. En ocasiones, se retrasan en los pagos o, incluso, dejan de hacerlos. Esto agrava los problemas económicos de la unidad monoparental.

Un informe realizado por la ONU Mujeres (2019) ilustra esta realidad, a partir de un análisis comparado entre distintas zonas del mundo. Concluye que, si estas familias no disponen de estructuras de apoyo y medidas de protección social, como servicios de cuidado infantil, viviendas protegidas, deducciones fiscales o prestaciones familiares, la incidencia de la pobreza se acentúa. De hecho, señala que las diferencias entre países que se identifican en el informe, en cuanto a las tasas de pobreza de las familias monoparentales, se explican atendiendo, precisamente, a las medidas de política social que los países implementan.

Como la principal fuente de ingresos de una familia es el trabajo remunerado, la posición que ocupan las madres solas en el mercado laboral constituye un factor determinante en su situación económica. Estas mujeres tienen una actividad laboral alta y una fuerte orientación al trabajo, como revelan ciertos estudios (Flaquer, Almeda y Navarro, 2006; ONU Mujeres, 2019). Sin embargo, su participación en el mercado laboral se concentra en los sectores económicos de mayor precariedad. Esto implica salarios más bajos, trabajos estacionales o de temporada y jornadas parciales (Sastre, 2015).La actividad económica irregular, en la economía sumergida, es acentuada en este colectivo, lo que impide el acceso posterior a prestaciones de desempleo.

En un estudio de Flaquer (2004) se constató que las madres solas son más vulnerables ante el crecimiento del desempleo, con las consecuencias negativas que ello implica en sus niveles de renta. Un informe reciente sobre exclusión y desarrollo social en España (Fundación FOESSA, 2019) indica que los hogares monoparentales y de personas inmigrantes son los que muestran mayor tasa de desempleo. En aquellos casos en los que confluyen ambas características, las tasas aumentan. El informe toma como referencia los datos de 2018. Señala que, ese año, en el 12\% de los hogares monoparentales el sustentador principal sufría inestabilidad laboral grave. Los autores asocian este problema con las carencias estructurales del mercado de trabajo y el bajo nivel educativo de estos hogares. Revelan que en el $41,2 \%$ de los hogares monoparentales encuestados, había alguna 
Fernández-Martínez y Avilés-Hernández

persona sin educación obligatoria terminada. La incidencia de este problema educativo era mayor entre los hogares encabezados por una mujer a partir de 45 años, que buscaba empleo o percibía una pensión.

La mala situación económica provoca, en ocasiones, otros problemas en estas familias. Uno de ellos guarda relación con la vivienda. En general, estos hogares presentan una tasa menor de vivienda en propiedad, una tasa más alta de alquiler a precio de mercado y una tasa también más alta de vivienda cedida (Malgesini, 2018). Igualmente, presentan cifras elevadas de pobreza energética y retrasos en los pagos de los gastos correspondientes a la vivienda. En el estudio que llevó a cabo la Fundación FOESSA (2019), averiguaron que casi la mitad de los hogares monoparentales encuestados vivían de alquiler. Cerca del 30\% tenía gastos excesivos en relación a la vivienda, y un 25\% no disponía de dinero suficiente para hacer frente a sus costes.

\section{-Área psicosocial}

En lo referente a la segunda área, la psicosocial, es frecuente la aparición de algún trastorno emocional en las madres. Esto se da especialmente al inicio de la monoparentalidad, que es cuando todavía se están adaptando a la nueva situación. Los trastornos más comunes son depresión, estrés y ansiedad. En menor medida, se produce fragilidad emocional y alteraciones del sueño o la alimentación (Morgado, González y Jiménez, 2003).

El tipo de trastorno, así como su intensidad, se asocia con varios factores. Uno de ellos es la causa que origina la monoparentalidad. Son más graves cuando esta sobreviene de forma imprevista. Por ejemplo, cuando se produce un divorcio inesperado o la muerte repentina de uno de los miembros de la pareja. También, son más graves en situaciones especiales como las que representan los casos de violencia de género. Por eso, estas familias monoparentales son reconocidas por diversas legislaciones como una categoría especial (Ramón, 2019). Otros elementos que influyen son el número de hijos que hay en el hogar, su edad, las características sociodemográficas de la madre o la posible existencia de litigios con la expareja.

Una vez que ya se ha entrado en la monoparentalidad, los trastornos que aparecen se suelen asociar con el estrés y el agotamiento que implica para el progenitor asumir todas las responsabilidades familiares. En ocasiones, las madres que son jefas de familia y están solas tienen que hacer frente a una importante sobrecarga de tareas. También, a serias dificultades para compatibilizar su jornada laboral con los cuidados y atenciones que requieren sus hijos. Esta sobrecarga de roles genera los trastornos emocionales descritos, además de conflictos entre los miembros de la familia (Avilés, 2018). Las mujeres pueden sentir ansiedad ante la toma de decisiones si no tienen con quién compartir sus 
miedos, incertidumbres y opiniones acerca de cómo hacer las cosas. Esta sensación de soledad puede hacer que caigan en conductas parentales inconsistentes.

Las madres adaptan sus estilos parentales a la nueva situación familiar. Desarrollan estrategias que les permitan compatibilizar con éxito la pluralidad de roles, y mantener el equilibrio dentro de la familia. Estas estrategias suelen responder a la historia personal de cada mujer y a las circunstancias concretas de la familia y sus miembros, tal y como han constatado Domínguez, González, Navarrete \& Zicavo (2019).

Los hijos de estas familias están expuestos a problemas de tipo psicosocial por varias razones. Primero, es evidente que la monoparentalidad, en sí misma, impacta sobre ellos, especialmente cuando no entienden o no aceptan lo que ha sucedido. El choque es mayor si el progenitor con el que no conviven se distancia. Esto puede provocar sentimientos de abandono en los hijos. Segundo, al pertenecer a un grupo monoparental, están expuestos a las vicisitudes por las que atraviesan estas familias a nivel económico, laboral, etc. Tercero, son niños que tienen un papel más protagonista dentro del hogar. Al faltar un progenitor, su ayuda se convierte en fundamental, sobre todo si son adolescentes. De hecho, asumen un mayor número de tareas domésticas y responsabilidades que los hijos de otras familias.

Estas cuestiones hacen que los hijos de las familias monoparentales sean más vulnerables que el resto. Tienen mayor probabilidad de padecer algún trastorno como depresión, ansiedad, baja autoestima, aislamiento, agresividad o fracaso escolar. Un estudio reciente ha constatado, por ejemplo, que los adolescentes que pertenecen a estas familias presentan problemas en su desarrollo social (López-Mero y Pibaque-Tigua, 2018). Esto se refleja, apunta el estudio, en el ámbito educativo, concretamente en el rendimiento escolar, así como en la interacción con sus iguales y en la participación social. Algunos análisis han puesto de manifiesto que el menor rendimiento escolar de los niños no se debe tanto a que la familia sea monoparental, sino a otras cuestiones (ONU Mujeres, 2019). Algunas que señalan son la variación en la intensidad del trabajo del progenitor con el que viven, la duración de la pobreza de ingresos, los altos niveles de privación material y la menor calidad de las escuelas a las que asisten.

\section{Los Servicios Sociales de Atención Primaria en España}

En España, el sistema público de Servicios Sociales se define como el conjunto de servicios y prestaciones que, junto a otros elementos del Bienestar Social, tiene una doble finalidad. Por una parte, la promoción y desarrollo pleno de todas las personas y grupos sociales, para que alcancen mayores niveles de bienestar y calidad de vida en el entorno de la convivencia. Por otra parte, la prevención y eliminación de las causas que conducen a la exclusión y marginación social (Ministerio de Trabajo y Asuntos Sociales, 2007). 
Para alcanzar esta doble finalidad, el Ministerio competente establece cuatro objetivos:

1. Garantizar el desarrollo pleno y libre de los derechos de las personas y los grupos en igualdad.

2. Dar cobertura a las necesidades sociales, adecuándolas a los procesos de cambio de la realidad social.

3. Prevenir las circunstancias que originan la marginación.

4. Promover la plena inserción de las personas y los grupos en la vida comunitaria.

La consecución de estos objetivos se alcanza a través de las estructuras y servicios de las distintas Administraciones Públicas (estatal, autonómica y local), con la participación de entidades privadas y del tercer sector.

El Catálogo de Referencia de Servicios Sociales en España (Ministerio de Sanidad, Servicios Sociales e Igualdad, 2013), establece que las actuaciones desarrolladas desde los servicios sociales deben basarse en los siguientes principios: universalidad, responsabilidad pública, igualdad, equidad, prevención y dimensión comunitaria, promoción de la autonomía personal, atención personalizada e integral, inserción y normalización, proximidad, solidaridad, calidad, participación, cooperación y colaboración.

La actuación del Sistema Público de Servicios Sociales se articula en una estructura, que presenta dos niveles de intervención diferenciados:

1. Servicios Sociales de Atención Primaria, igualmente denominados de base, comunitarios, básicos, de primer nivel o generales.

2. Servicios Sociales Especializados, conocidos también como específicos, de nivel secundario o de atención especializada.

De acuerdo con Setién y Arriola (1997), los Servicios Sociales de Atención Primaria se caracterizan por:

- Constituir la estructura básica del sistema, siendo la puerta de entrada a este.

- Tener carácter territorial, dirigiendo su actuación a una zona geográfica concreta.

- Ser de carácter descentralizado y polivalente, puesto que dan respuesta a las diversas necesidades del entorno, acercando los recursos a la ciudadanía.

- Constituir la principal vía de acceso hacia los servicios sociales especializados.

- Vertebrar el tejido social, pues impulsan la vida de la comunidad, favorecen la creación de redes sociales y potencian las ya existentes. 
- Fomentar la participación de toda la comunidad, y la coordinación con los demás sistemas de protección y agentes que intervienen en el bienestar.

- Ser la principal fuente de información para la planificación de las políticas sociales, mediante la detección de necesidades.

Los Servicios Sociales de Atención Primaria, desde la creación del Plan Concertado de Prestaciones Básicas de Servicios Sociales en el año 1988, prestan, entre otros, los servicios de información y orientación, apoyo a la unidad convivencial, ayuda a domicilio, alojamiento alternativo y prevención e inserción social. Además, cuentan con prestaciones económicas no periódicas de emergencia social. Su actuación se desarrolla desde los Centros de Servicios Sociales Comunitarios, que constituyen el equipamiento fundamental de la Red Pública de Servicios Sociales.

Con respecto a los Servicios Sociales Especializados, Setién y Arriola (1997) indican que son servicios dirigidos a personas y colectivos con problemáticas definidas, que precisan de una intervención específica. Los servicios especializados ofrecen información, valoración y diagnóstico; terapia y rehabilitación psicosocial; alojamiento alternativo; y gestión de prestaciones económicas de carácter periódico y no periódico. Para implementar dichas actuaciones, existen equipamientos especializados como: centros básicos de atención, centros de día, residencias, albergues, casas de acogida, escuelas infantiles, comunidades terapéuticas, centros de menores con medidas judiciales, etc.

Nuestro estudio se focaliza en los Servicios Sociales de Atención Primaria. A continuación, exponemos, brevemente, la actuación habitual de los profesionales de Trabajo Social con las familias monoparentales cuando estas acceden al Sistema Público de Servicios Sociales.

Una vez recibido el caso, desde la Unidad de Trabajo Social de zona se recoge la demanda y se realiza un estudio de la situación. Para ello, se recopila la información necesaria a través, entre otras, de las técnicas de la entrevista, observación, análisis documental y visita domiciliaria. Posteriormente, se realiza el diagnóstico de la situación y se valora el recurso más idóneo para atender las necesidades planteadas. En la mayoría de ocasiones, la intervención con el grupo monoparental se realiza desde la Unidad de Trabajo Social, siendo necesaria, y de vital importancia, la coordinación con otros profesionales, programas, servicios y entidades. Es posible que, durante la intervención, la demanda se derive, bien a programas especializados del propio centro de Servicios Sociales de Atención Primaria, o bien a otros departamentos. Estos últimos pueden ser del Ayuntamiento, de los Servicios Sociales Especializados de la Comunidad Autónoma, de otras administraciones públicas o de entidades sin ánimo de lucro de la zona. 


\section{Metodología}

\section{Objetivos de la investigación}

El estudio tiene como objetivo general analizar la situación de necesidad que viven las familias monoparentales con jefatura femenina, usuarias de Servicios Sociales de Atención Primaria en España. Este objetivo se concreta en los siguientes específicos:

- Identificar las necesidades sentidas y expresadas por las mujeres al frente de estas familias.

- Conocer las estrategias y recursos que emplean para la gestión de sus necesidades.

- Identificar propuestas y líneas de intervención, desde la óptica de las propias mujeres, para la resolución de su situación de necesidad.

\section{Diseño metodológico}

Para la consecución de los objetivos, se diseñó un estudio exploratorio, sincrónico y de ámbito local. Se optó por una metodología cualitativa, ya que pretendíamos identificar y comprenderlas interpretaciones, pensamientos y sentimientos de las mujeres monoparentales usuarias de servicios sociales primarios. Se quería conocer la experiencia vivida, facilitando la expresión, con sus palabras, de lo que pensaban y sentían en ese momento. Como técnica de recogida de información, se utilizó la entrevista en profundidad semiestructurada. Esta se realizó a 10 mujeres que respondían al perfil. Todas eran usuarias de Servicios Sociales de Atención Primaria en un ayuntamiento de España. Este se sitúa al sureste del país y atiende a un total de 71.890 personas, 10,9\% extranjeras. El análisis, por tanto, se basa en un estudio de caso. Los resultados que se alcanzan, en contraste con los datos estadísticos que arrojan las fuentes oficiales, permiten ilustrar la situación de estas familias en España.

En el momento de la entrevista, las mujeres del estudio tenían a su cargo hijos menores de edad, o mayores de 18 años incapacitados judicialmente o en situación de dependencia. La selección de las entrevistadas se llevó a cabo de la siguiente manera: primero, se revisó el listado de mujeres que encabezaban familias monoparentales y que durante un trimestre habían acudido a su trabajador/a social de zona. Segundo, se distribuyeron en grupos según la causa que había provocado la monoparentalidad. Tercero, se seleccionó una mujer de cada grupo de manera aleatoria, a fin de tener un discurso amplio, rico en matices, que englobara a mujeres que son monoparentales por diversas razones. 
Fernández-Martínez y Avilés-Hernández

El contacto inicial con cada una se realizó por teléfono. En ese momento, se explicó la finalidad de la investigación, se pidió el consentimiento y se fijó una fecha para la entrevista en persona. Esta entrevista se llevó a cabo posteriormente, en el propio Centro de Servicios Sociales de Atención Primaria. El trabajo de campo fue intenso y se desarrolló durante el último trimestre del año.

Los objetivos del estudio se concretan en cuatro dimensiones de análisis que se exponen en la Tabla 2. Estas vertebran el guión que se utilizó para la recogida de la información.

Tabla 2. Dimensiones y categorías de análisis.

\begin{tabular}{cc}
\hline Dimensión 1. Identificación de la familia & Dimensión 2. Necesidades sentidas \\
Causa de la monoparentalidad & Económicas \\
Edad & Laborales \\
Nacionalidad & De conciliación \\
Ocupación de la madre & Emocionales \\
Número de hijos & Sobrecarga \\
Nivel de ingresos & Otras \\
\hline Dimensión 3. Recursos & Dimensión 4. Propuestas de intervención \\
Apoyo informal & A nivel económico \\
Apoyo formal & A nivel laboral y de conciliación \\
Institución que presta el apoyo & Otras propuestas \\
\hline
\end{tabular}

Fuente: elaboración propia

\section{Participantes}

En la Tabla 3 se recoge información descriptiva sobre las mujeres que participaron en el estudio. 
Fernández-Martínez y Avilés-Hernández

Tabla 3. Perfil socio-demográfico de las mujeres entrevistadas.

\begin{tabular}{|c|c|c|c|c|c|c|c|}
\hline Entrevistada & $\begin{array}{c}\text { Causa de la } \\
\text { monoparentalidad }\end{array}$ & Nacionalidad & $\begin{array}{l}\text { Edad } \\
\text { madre }\end{array}$ & $\begin{array}{l}\text { Edad } \\
\text { hijos }\end{array}$ & $\begin{array}{c}\text { Nivel } \\
\text { instrucción } \\
\text { madre }\end{array}$ & $\begin{array}{c}\text { Ocupación } \\
\text { madre }\end{array}$ & $\begin{array}{c}\text { Ingresos } \\
\text { mensuales } \\
\text { (en euros) }\end{array}$ \\
\hline E1 & $\begin{array}{c}\text { Separación de } \\
\text { hecho }\end{array}$ & Colombiana & 33 & 9,6 y 2 & Secundarios & Desempleo & 550 \\
\hline E2 & $\begin{array}{l}\text { Causas sociales: } \\
\text { emigración del } \\
\text { marido }^{1}\end{array}$ & Nigeriana & 34 & 10,6 y 1 & Sin estudios & Desempleo & 400 \\
\hline E3 & $\begin{array}{c}\text { Causa sociales: } \\
\text { encarcelación de la } \\
\text { pareja }\end{array}$ & Boliviana & 36 & 16,14 y 6 & Sin estudios & $\begin{array}{l}\text { Economía } \\
\text { sumergida }\end{array}$ & 500 \\
\hline E4 & Separación judicial & Española & 58 & $19^{2}$ & Sin estudios & $\begin{array}{c}\text { Inactiva. } \\
\text { Cuidadora }\end{array}$ & 1.393 \\
\hline E5 & Madre soltera & Española & 33 & 4 meses & Secundarios & $\begin{array}{l}\text { Empleada } \\
\text { de hogar }\end{array}$ & 400 \\
\hline E6 & Divorcio & Española & 37 & 15 y 7 & Secundarios & $\begin{array}{l}\text { Economía } \\
\text { sumergida }\end{array}$ & 762 \\
\hline E7 & Divorcio & Española & 36 & 8 & Secundarios & $\begin{array}{l}\text { Economía } \\
\text { sumergida }\end{array}$ & 300 \\
\hline E8 & Madre soltera & Boliviana & 39 & 13 y 9 & Universitarios & Desempleo & 426 \\
\hline E9 & Abandono $^{3}$ & Marroquí & 41 & 5 y 3 & Sin estudios & $\begin{array}{l}\text { Economía } \\
\text { sumergida }\end{array}$ & 300 \\
\hline E10 & Viudedad & Española & 48 & 10 & Primarios & Inactiva & 900 \\
\hline
\end{tabular}

Fuente: elaboración propia

Las causas de monoparentalidad son diversas, pues se estableció esa intencionalidad en la selección. De las mujeres entrevistadas, cinco eran extranjeras: una colombiana, una nigeriana, dos bolivianas y una marroquí. En lo referente al número de hijos, tres mujeres tenían a su cargo tres hijos, por lo que eran familias numerosas. Otras tres mujeres tenían dos hijos y cuatro solamente uno. La edad de las mujeres en el momento de la entrevista oscilaba entre los 33 y 58 años. Su edad cuando se originó la monoparentalidad se encontraba entre los 27 y 47 años. El intervalo de edad de los hijos iba desde los 4 meses hasta los 19 años. Con respecto al nivel de instrucción de las mujeres, cuatro no finalizaron los estudios primarios, una sí los terminó, cuatro cursaron estudios secundarios y una realizó estudios universitarios. Con relación a la ocupación, todas estaban en situación de desempleo o inactividad, salvo una que trabajaba como empleada de hogar cotizando a la

1 Emigración del marido a Nigeria por motivos laborales.

2 Hija dependiente

3 Su marido continúa en paradero desconocido.

Prospectiva. Revista de Trabajo Social e intervención social • No. $30 \bullet$ jul.-dic. $2020 \bullet$ pp. 145-173 e-ISSN: 2389-993X • https://doi.org/10.25100/prts.v0i30.8855 
Fernández-Martínez y Avilés-Hernández

Seguridad Social, coste que asumía ella misma. Cuatro mujeres, aunque desempleadas, trabajaban de forma esporádica en la economía sumergida como camareras, empleadas de hogar y/o cuidadoras de personas dependientes. Según indicaron, las personas para quienes trabajaban se negaban a regularizar su situación laboral.

Todas las mujeres entrevistadas percibían en el momento de la entrevista prestaciones públicas de los diferentes sistemas de protección social españoles: sistema estatal de empleo, seguridad social, servicios sociales, agencia tributaria, etc. Algunas de ellas, de dos o tres sistemas diferentes a la vez. La entrevistada 4, por ejemplo, recibía a la mayor parte de sus ingresos de las prestaciones públicas que tenía su hija como consecuencia de su situación de dependencia y discapacidad. La entrevistada 10 los percibía de la pensión de viudedad y orfandad. Otras entrevistadas, como la 7 y 8, recibían el subsidio de desempleo. Las entrevistadas 2 y 6 cobraban la renta básica de inserción, esta última también el anticipo del fondo de garantía de alimentos. La entrevistada 1 recibía la ayuda periódica de protección e inserción social. La entrevistada 5, al estar trabajando de forma legal, cobraba la deducción de maternidad anticipada por ser madre trabajadora de un niño menor de 3 años. Todas recibían la prestación familiar por hijo a cargo.

\section{Análisis de la información}

Se realizó a través de un análisis de contenido. Cada entrevista fue trascrita y, posteriormente, revisada para observar repeticiones entre las respuestas que los sujetoslas entrevistadas-habían dado a cada pregunta. Esto ha permitido establecer coincidencias e integrar, en un mismo discurso, los distintos contenidos o informaciones que se desprenden de las palabras de cada entrevistada.

\section{Resultados}

\subsection{Necesidades sentidas}

\subsubsection{Económicas y laborales}

Las entrevistadas manifiestan que las principales necesidades con que se encuentran son a nivel económico, en cuanto que son las únicas sustentadoras de la unidad familiar. Enfatizan la idea de que sus ingresos son insuficientes para cubrir los gastos más elementales del hogar y del cuidado de sus hijos, como alimentación, suministros básicos, etc.:

No tengo para lo que mis hijos necesitan, ni para lo más básico... (E1).

Quiero hacer algo a mis hijos y no puedo, porque no tengo ni para alimentación, ni para

lo que ellos necesitan, ni para lo más básico... (E2). 
Fernández-Martínez y Avilés-Hernández

Cuando me divorcié me di cuenta que yo sola no llegaba, no podía hacer frente a todo: comida, gasto de luz, comunidad, hipoteca... (E6).

Con lo que obtengo no me alcanza para el alquiler, ni para pagar la luz y el agua... solo para la alimentación, y a veces ni para eso... (E8).

Las necesidades económicas que presentan están estrechamente vinculadas a las necesidades laborales. De hecho, las madres entrevistadas indican que la principal causa de sus dificultades económicas se encuentra en la ausencia de empleo o en la precariedad del mismo:

Si tuviera un trabajo, no tendría problemas económicos ni necesitaría ayudas... (E1).

El problema es no tener un trabajo seguro para yo defender a mi hijo. (E5).

El trabajo que tienen se caracteriza, precisamente, por la inestabilidad y por desarrollarse en un contexto de economía sumergida:

No tengo nada estable... trabajo cuando me llaman a limpiar. (E3).

Nunca he encontrado estabilidad en el empleo, además en la mayoría de sitios donde trabajé ni me dieron de alta... (E7).

Cuatro madres indican que sus problemas económicos también se derivan del incumplimiento, por parte de los padres de los menores, de sus obligaciones económicas:

Si el padre de mis hijos pagara la pensión y su parte de la hipoteca, con lo que yo me saco podríamos vivir dignamente... (E6).

\subsubsection{Conciliación de la vida laboral y familiar}

La conciliación es otro de los elementos clave para entender la situación económica y laboral de estas mujeres. Es más, estas tres dimensiones están unidas: economía-empleoconciliación. La economía depende mayoritariamente del empleo, pero la conciliación de este con los cuidados que requieren los hijos limita el acceso de las mujeres al mercado laboral, con lo que se acentúa la situación de necesidad económica. La mayoría de entrevistadas optan por empleos que, aunque precarios, les permitan atender a sus hijos:

Trabajo de lunes a domingo durmiendo en casa de una persona mayor, entro a las ocho de la tarde y salgo a la ocho de la mañana menos los lunes, miércoles y viernes que me encargo de limpiar la casa y hacerle la comida... no descanso ningún día y me dan 500 euros al mes... pero por lo menos me llevo a mi niña a dormir conmigo... (E3).

Es la pescadilla que se muerde la cola, mi economía depende de tener trabajo, pero ¿qué hago con los críos? No me puedo ir a trabajar a las fábricas, se entra a las 6:00 y se sale a las 14:00 y ¿con quién dejo a los críos a esa hora? (E6). 
Fernández-Martínez y Avilés-Hernández

La mayoría aprovechan el horario escolar para desarrollar sus actividades laborales:

Busco un empleo que coincida con el horario del cole de los niños. (E1).

Aprovechaba que la niña estaba en el colegio y en ese horario yo iba limpiando dos o tres horas, nunca he podido coger más horas, una casa por día, siempre aprovechando el hueco. (E4).

Trabajo limpiando casas, dejo a los críos en el colegio y entro a las 9:30, y trabajo hasta las 12:30 y después los recojo a las 14 horas... (E6).

Expresan la imposibilidad de aceptar ciertos trabajos por las dificultades de conciliación:

Me toca buscar a una persona que se quede encargada de cuidar a mis hijos mientras yo trabajo... hay tardes que trabajo 10 horas y con lo que le pago a la señora me gano 10 euros. (E1).

Cuando me separé tuve que dejar el trabajo que tenía en el restaurante por el horario, el horario no era compatible con los críos, con el pequeño... que tenía dos años... (E6).

He tenido que rechazar trabajos porque no tenía donde dejar a los niños. (E8).

Algunas mujeres reconocen que si aceptan trabajos precarios es porque les dan facilidades para conciliar:

Sé que me pagan poco por lo que trabajo, pero puedo llevarme a la niña conmigo. (E3).

Tengo mucha suerte porque en las casas en que trabajo me dejan llevarme al bebé conmigo. (E5).

\section{Emocionales y psicológicas}

La situación de monoparentalidad tiene un impacto fuerte sobre las mujeres entrevistadas a nivel emocional y psicológico. Hablan de tristeza, sentimientos de soledad, miedo, inseguridad, depresión, ansiedad y somatizaciones del estrés como pérdida de peso y problemas para dormir. En las entrevistas se observa que estas circunstancias están vinculadas a dos cuestiones claves. La primera, es el ajuste psicológico que conlleva la pérdida de la pareja y la transición hacia un modelo de familia monoparental:

Es difícil separarse y más cuando no te lo esperas. (E4).

Dolor, cuando él se marchó solo sentía dolor. (E6).

Cuando él se marchó sin avisar, pasé mucho miedo sin saber dónde estaba, si le había pasado algo, no lo entendía, el día antes bien y al otro se va y nunca más he sabido de él... me costó una depresión... lloré mucho...(E9).

Sentía un vacío muy grande. (E10).

La segunda, es la sobrecarga de responsabilidades que conlleva ser madre sola. Al ser el único progenitor en el núcleo familiar, tienen que asumir en soledad todos los roles: 
Fernández-Martínez y Avilés-Hernández

proveedora de recursos, encargada de las tareas del hogar, responsable de la educación y cuidados de los hijos, etc. Algunas madres manifiestan que esta situación les provoca miedo e inseguridad:

Siento que soy yo sola para todo. (E1).

Es difícil estar sola con los niños, y tener que trabajar para que les falte de nada, y cuidarles, y la casa... llega un momento que una se siente ofuscada. (E2).

Encontrarte sola para cuidar a tu hija, incluso ahora, en ocasiones, me sigo encontrando agobiada. (E4).

No puedes bajar la guardia, toda la responsabilidad recae sobre ti. (E6).

Miedo, tengo miedo porque estoy sola para sacar adelante a mis hijos. (E9).

En algunas, el impacto a nivel psicológico es tan importante, que genera episodios de estrés, ansiedad y otros problemas de salud:

En diciembre me dio un ataque de ansiedad, me asusté mucho, creí que me moría, no podía respirar, me dolía el pecho, tuve que el ir al médico. (E2).

$\mathrm{Al}$ poco tiempo de que mi marido entró en prisión comenzaron a darme ataques epilépticos, el médico me dijo que estaban causados por el estrés de mis circunstancias.

(E3).

Tengo ansiedad, pero como le doy pecho al bebé no puedo tomar medicación. (E5).

He perdido mucho peso como consecuencia del estrés. (E9).

Con respecto a si han tenido que recibir asistencia sanitaria como consecuencia de sus problemas emocionales, la mitad ha reconocido que sí. En el caso de la entrevistada 9, recibió asistencia psicológica desde servicios sociales porque, al ser extranjera y no estar trabajando, le desactivaron la tarjeta sanitaria. La entrevistada 3, que ha desarrollado epilepsia, continúa en tratamiento farmacológico. La entrevistada 4 asistió a consulta de psiquiatría y psicología por depresión durante cinco años, en la actualidad continúa con tratamiento farmacológico en seguimiento por el médico de familia. La entrevistada 2 recibe tratamiento por ansiedad y la 8 asistencia psicológica.

Con respecto a los menores, solo algunas de las entrevistadas han señalado que sus hijos han presentado este tipo de problemas, generalmente vinculados con la pérdida o ausencia del padre. Las entrevistadas 1 y 6 señalan que sus hijos mayores, tras la separación, tuvieron que recibir asistencia psicológica sin tratamiento farmacológico precisamente por este motivo. La entrevistada 2 explica que sus hijos echan de menos al padre pero que no están tristes, pues piensan que, cuando este regrese, la situación familiar mejorará. La entrevistada 8 señala que su hijo menor, que no fue reconocido legalmente por el padre, pregunta continuamente por él. La entrevistada 9 señala que, al principio, los dos menores echaban de menos a su padre y se mostraban tristes. 
Fernández-Martínez y Avilés-Hernández

\section{Otras necesidades}

Algunas entrevistadas aluden a los problemas judiciales que están protagonizando, ligados a procesos de separación o divorcio, custodia de los menores y reclamación de las pensiones de alimentos por impago. En los casos de divorcio o separación que se han entrevistado, los padres de los menores se han desentendido de sus obligaciones económicas. Las madres señalan que estos impagos se sostienen hasta que se produce el juicio y se dicta sentencia sobre la custodia:

Comenzó a pagar la pensión de alimentos después del juicio de la custodia. (E4).

Cuando se marchó me dijo que no me iba a dar un duro hasta que hubiese sentencia, y así lo hizo. (E6).

Aún en el caso de existir una sentencia, hay padres que no pagan o ingresan menos de lo establecido por sentencia. Fomentan, de esta manera, la situación de precariedad económica que describen las madres entrevistadas:

Le he denunciado dos veces por no pagar la pensión de alimentos y aún no he conseguido que la pase, el mes que viene volveré a denunciarle... (E1).

La pensión de alimentos la paga cuando quiere, nunca ha abonado los gastos extraordinarios ni ha revalorizado la cuantía... (E6).

Las madres añaden que los procedimientos judiciales se prolongan demasiado en el tiempo:

Desde que nos separamos, solicité y me asignaron el abogado de oficio y después metieron los papeles en el juzgado y salió la sentencia..., pasó más de año y medio. (E1).

Es posible identificar en el discurso de las entrevistadas alusiones a dos tipos de necesidades adicionales. Estas se relacionan con la vivienda y la falta de apoyo familiar. En lo referente a la primera, las entrevistadas no viven situaciones de infravivienda, hacinamiento ni condiciones insalubres o problemas de habitabilidad. Sin embargo, sí existen otras problemáticas que las sitúan en un contexto de precariedad residencial. En el caso de las entrevistadas 1, 2 y 7, existe un proceso de ejecución hipotecaria. Manifiestan su inquietud cuando se aproxime el momento en el que tengan que abandonar sus casas:

De dónde voy a sacar para pagar un alquiler cuando me echen (E1).

No sé qué voy a hacer, o a donde voy a ir... (E2).

Estoy muy preocupada, no sé lo que voy a hacer, ¿a dónde voy a ir? (E7).

El resto disponen de vivienda en las siguientes condiciones: las entrevistadas 8 y 9 viven de alquiler, las entrevistadas 5 y 6 tienen la vivienda sujeta a un préstamo 
Fernández-Martínez y Avilés-Hernández

hipotecario, las entrevistadas 4 y 10 tienen la vivienda en propiedad sin cargas, y la entrevistada 3 alquila una habitación en una vivienda compartida con otras unidades familiares con las que no tiene relación de parentesco ni amistad. El coste de la vivienda, y su pago, supone una preocupación para todas, ya que implica uno de los mayores gastos a los que tienen que hacer frente.

Las entrevistadas que abonan préstamo hipotecario manifiestan que reciben ayuda de sus familias para el pago de la hipoteca:

Cuando me llama el del banco, de que no me pueden aguantar más la letra, llamo a mi madre para que me ingrese la parte que me falta. (E6).

Y quienes alquilan temen no poder hacer frente al alquiler:

Un plato de comida te lo da cualquiera, pero ¿quién te da un hogar? (E9).

En lo referente al apoyo familiar, hay que señalar que es un recurso para las mujeres entrevistadas muy importante. Por eso, su ausencia constituye un problema. Las mujeres que carecen de este apoyo son, principalmente, las extranjeras, ya que sus familias continúan en el país de origen. Si disponen de algún familiar en España, el apoyo es escaso y/o puntual:

Si mi familia estuviese aquí yo no tendría problemas, mientras yo trabajo se ocuparían de mis hijos. (E1).

Yo no tengo a nadie aquí y eso es lo que ahora duele más (tras la marcha de su marido por motivos laborales). No tengo donde ir, donde acudir (...) Cuando no tienes a nadie todo es más difícil. (E2).

Estoy sola con mi hija, toda mi familia está en Bolivia. (E3).

Mis hermanos también viven aquí, pero somos inmigrantes y cada uno tiene su vida y sus hijos, no puedes ser una carga para ellos. (E9).

\subsection{Gestión de sus necesidades}

\subsubsection{Red de apoyo informal: familia y amistades}

Tras ahondar en las necesidades de las mujeres entrevistadas, se les ha preguntado por los apoyos y recursos con los que cuentan para afrontar su situación. Cinco manifiestan que la principal ayuda, en todos los sentidos, procede de sus familiares, especialmente de la madre. Señalan que no han tenido ni que pedirla. Sus propios familiares han tomado la iniciativa y se la han ofrecido sin más. Con respecto a la ayuda económica y en especie, indican lo siguiente: 
Fernández-Martínez y Avilés-Hernández

Mi madre me llama y me dice: «nena, ¿tienes para la hipoteca de este mes?», y me ingresa lo que puede, 100, 200 euros... cuando voy a verla me tiene preparadas las bolsas de comida y cosas para el bebé. (E5).

Mi principal ayuda ha sido mi familia, mis padres y mis hermanas, pero sobre todo mi madre, no tengo que pedir nada, ella me ofrece, está pendiente de si necesito comida, o algo para los críos, si me ha venido el recibo de luz, si me falta para la hipoteca... (E6).

El apoyo que reciben también es a nivel emocional y de conciliación:

Los jueves por la tarde tengo una casa a la que voy tres horas, el crío pequeño se lo dejo a mi hermana y si ella no puede se lo llevo a mi madre. (E6).

Mi hermana me recoge a los críos del colegio si yo no puedo. (E9).

Las madres que reciben apoyo de sus familias afirman que es de manera regular. Junto a la figura de la madre, aparece la de otras mujeres de la familia como hermanas, cuñadas y tías por vía materna, por lo que la ayuda está claramente feminizada:

Para desahogarme hablo con mi hermana y con mi cuñada, evito hablar con mi madre para no preocuparla más, sé que ella sufre mucho. (E7).

Como ya se ha señalado, algunas mujeres entrevistadas carecen de apoyo familiar, lo que, en sus palabras, constituye un problema. Tres entrevistadas señalan que no tienen familia en España. Dos comentan que, aunque tienen familiares, su apoyo no es consistente, pues tampoco ellos cuentan con una situación desahogada. El mayor riesgo de pobreza que padecen los núcleos monoparentales de origen extranjero puede explicarse por la ausencia o inconsistencia de este apoyo familiar:

No se puede estar continuamente pidiendo porque tampoco están bien. (E8).

No les puedo pedir a mis hermanos, ellos tienen sus hijos y sus problemas, sé que un plato de comida nunca me faltaría, pero otra cosa..., no pueden. (E9).

También aparecen en el discurso, como figuras de apoyo, amistades y vecinos. Todas las mujeres entrevistadas mencionan que se trata de un importante apoyo. Sin embargo, este es más intenso y constante entre las mujeres españolas. En este caso, se da en cuestiones de apoyo emocional y/o material, y en relación con los menores, sobre todo en llevarlos y recogerlos de la escuela:

Si estoy enferma mi amiga viene a casa y lleva a los niños al cole y después me los recoge. (E1).

Mis vecinas, que en verdad son mis amigas, me ayudan mucho, me compran hasta comida y pañales para el bebé. (E5).

Mi vecina, cuando sabe que estoy mal, me compra comida y me ha llegado a dar 30 euros para que compre lo que necesito. (E7). 
Me he apoyado mucho en mis amigas, nunca me dejan sola. (E10).

En el caso de las mujeres extranjeras, el apoyo de las vecinas y amistades no es consistente ni regular; evitan recurrir a él con frecuencia.

\subsubsection{Red de apoyo formal: Instituciones}

Dos entrevistadas manifiestan que nunca antes habían acudido a servicios sociales a solicitar ayuda porque contaban con la de sus familias. Las ocho mujeres restantes señalan que acuden a servicios sociales con regularidad. En aquellos casos en los que no existe apoyo familiar o este es insuficiente, existe una mayor frecuencia en la demanda de ayuda formal. Además de acudir a Servicios Sociales de Atención Primaria, todas las mujeres han acudido o acuden a instituciones de otros sistemas de protección social.

Cuando las mujeres entrevistadas se refieren al apoyo institucional, señalan que la ayuda solicitada (necesidades expresadas o demandadas) a los Servicios Sociales de Atención Primaria es de diversa naturaleza. Se refiere a información y orientación, prestaciones económicas, ayudas de alimentación y medicación, ayudas vinculadas a la vivienda, material didáctico y escolar, empleo y formación, así como apoyo emocional y/o asistencia psicológica, y servicios de conciliación de la vida familiar y laboral. En el resto de organismos públicos españoles han solicitado las prestaciones y/o los servicios que ofertan.

Con respecto a la ayuda recibida desde las diferentes instituciones, comentan que tiene un carácter puntual y es insuficiente para dar respuesta a la situación de necesidad en que se encuentran, aunque les permite aliviar sus circunstancias en el momento concreto en que la perciben. Varias de las mujeres entrevistadas señalan que, aunque todas las ayudas son bien recibidas, la más importante ha sido el apoyo emocional, el tener un espacio de descarga y escucha. Incluso, dos de las mujeres, al finalizar las entrevistas que se han realizado para esta investigación, manifiestan sentirse más reconfortadas emocionalmente tras la conversación con la trabajadora social:

Esto me ha servido para sacar toda la rabia y la ira que aún me queda dentro. (E4).

Que bien me ha venido desahogarme, me voy limpia. (E9).

Para terminar, se pidió a las mujeres entrevistadas que realizaran propuestas sobre medidas que, desde los poderes públicos de España, podrían implementarse para mejorar la situación de familias como la suya. Todas han señalado medidas vinculadas a la cobertura de necesidades básicas, el acceso al empleo y la conciliación de la vida familiar y laboral. A continuación, se sintetizan las propuestas que han realizado: 
- Ayudas económicas que garanticen unos ingresos mínimos para la cobertura de las necesidades básicas del núcleo familiar mientras no mejore la situación.

- Ayudas económicas para madres trabajadoras con niños menores de cinco años.

- Incrementar y revalorizar la cuantía de las pensiones de supervivencia, que permita la cobertura de las necesidades básicas de la unidad familiar.

- Normalizar los requisitos de acceso a las ayudas y prestaciones, y agilizar el tiempo de tramitación.

- Universalización de los servicios y ayudas para menores; que se garantice que todos los menores, independientemente de su núcleo familiar, tengan acceso a becas de estudio, comedor, servicios de conciliación, etc.

- Medidas laborales que faciliten la inserción laboral de las madres solas:

- Formación y orientación para el empleo.

- Empleos protegidos para madres solas con dificultades.

- Horarios flexibles, coincidentes con horario escolar.

- Jornadas reducidas "minijobs".

- Servicios de conciliación subvencionados, con horarios flexibles y más amplios.

- Servicios de conciliación a domicilio: si la madre entra a trabajar a las 6:00 de la mañana, que una persona se dirija al hogar y se ocupe de los menores hasta que sea la hora de llevarlos al centro escolar o al servicio de conciliación al que acuda el menor.

- Garantizar el cumplimiento de las obligaciones del padre, agilizar los procesos judiciales de establecimiento de custodia y reclamación de alimentos.

- Creación de programas de atención integral y especializada para mujeres al frente de familias monoparentales.

- Habilitar espacios bajo la supervisión de profesionales para la creación de grupos de facilitación y ayuda mutua.

- Monoparentalidad como criterio de acción positiva en el acceso a recursos y servicios públicos.

\section{Conclusiones}

El análisis realizado constata que las necesidades de las familias monoparentales con jefatura femenina atendidas en Servicios Sociales de Atención Primaria giran en torno a tres ejes.

Eje 1: El primero es el económico, que es el más importante. En el estudio se constata que las dificultades de esta naturaleza son tan intensas, que existen problemas incluso para cubrir las necesidades básicas. Este hecho queda corroborado si se revisan las estadísticas oficiales. La Encuesta de Condiciones de Vida de 2019, que realiza el Instituto Nacional de Estadística de España, aporta datos sobre la situación de los hogares en 2018. Señala que, ese año, la renta media de los hogares monoparentales fue de 19.750 euros. Se 
Fernández-Martínez y Avilés-Hernández

encontraba muy por debajo de la media, situada en 28.417 euros. También era inferior a la que tenían los hogares biparentales con uno o más hijos dependientes, que ascendía a 35.437 euros. Esta misma encuesta revela que el 22,3\% de los hogares monoparentales afirmaba llegaba a final de mes con muchas dificultades y el 23,1\% con dificultad ${ }^{4}$. En los hogares biparentales con uno o más niños dependientes, llegaban a final de mes con muchas dificultades el 8,8\% y con dificultades el 16,1\%.

En lo que respecta a la carencia material, esta misma fuente indica que el 6,7\% de los hogares monoparentales en España no podía permitirse una comida de carne, pollo o pescado al menos cada dos días. El 53,5\% no tenía capacidad para afrontar gastos imprevistos. El 17,4\% había sufrido retrasos en los pagos de gastos relacionados con la vivienda principal, como el alquiler, recibos, etc., o en las compras a plazos. El 16,5\% no podía permitirse mantener la vivienda con una temperatura adecuada.

Estos datos contrastan con los que se obtienen para otro tipo de hogares. En el caso de los biparentales con uno o varios hijos dependientes, el 2,3\% no podía permitirse una comida de carne, pollo o pescado al menos cada dos días. El 30,8\% no tenía capacidad para afrontar gastos imprevistos. El 9,3\% había tenido retrasos en los pagos de gastos relacionados con la vivienda o las compras a plazos. El 6,8\% no podía permitirse mantener la vivienda con una temperatura adecuada.

En relación con estos datos sobre carencia material, el último informe de la European Anti Poverty Network (EAPN) (Llano, 2019) señala que, en 2018, sufrían en España privación material severa ${ }^{5}$ el $12,4 \%$ de las personas que pertenecían a un hogar monoparental. Se trata de la cifra más alta. Supone más del doble que la del conjunto de la población $(5,4 \%)$. Como dato adicional, se observa que es prácticamente la misma que en 2008 (12,5\%). Dentro de la gravedad, esta constante en el tiempo se interpreta como un dato positivo. En el resto de hogares la proporción de aquellos que tienen privación material severa ha aumentado a lo largo de la última década.

Eje 2: El segundo eje es el laboral. La situación de los hogares monoparentales se caracteriza por la inestabilidad, precariedad y baja intensidad. Corral (2008) explica que las madres solas, en ocasiones, no tienen estudios que les permitan acceder a un puesto de trabajo dignamente remunerado, ya que dedicaron todo su tiempo y esfuerzo a las tareas conyugales y domésticas. Además, no pudieron completar su formación académica ni realizarse laboralmente hablando, precisamente por esas responsabilidades familiares que asumieron. Un estudio realizado por Save the Children (Sastre, 2015), ilustra esta realidad.

4 Se trata de una escala de 1 a 6, donde 1 es "con mucha facilidad" y 6 es "con mucha dificultad".

5 Se considera que un hogar está en situación de carencia material severa cuando manifiesta carencias en, al menos, cuatro de nueve conceptos dados. 
Fernández-Martínez y Avilés-Hernández

Señala que más de la mitad de madres monoparentales de España no tiene empleo (el $52,0 \%)$, y muchas otras trabajan en condiciones de precariedad.

El escaso apoyo público en materia de conciliación lleva a lo que Tobío (2002) denomina "estrategias parciales de conciliación entre la vida laboral y familiar". Esto quiere decir que las madres ajustan su jornada o actividad laboral al horario escolar de sus hijos, trabajando menos horas o adaptando el horario a sus necesidades familiares. Las redes de apoyo informal se convierten en un elemento clave en la conciliación de la vida familiar y laboral, como apunta Méndez (2015).

Un estudio reciente (Ajenjo y García, 2019), ha analizado cómo las madres españolas que trabajan fuera de casa distribuyen el tiempo que dedican al trabajo no remunerado, esto es, a las tareas domésticas y al cuidado de sus hijos. El estudio revela que las madres monoparentales dedican menos tiempo al trabajo doméstico que las madres de familias biparentales. Esto se aprecia, sobre todo, en aquellas actividades domésticas más arduas y que permiten mayor flexibilidad, como la cocina, el cuidado de la ropa y la limpieza del hogar. En lo referente a las tareas de cuidado, no hay diferencias. Ambas madres dedican un tiempo similar al cuidado de sus hijos. Esto demuestra que las madres monoparentales que trabajan fuera de casa priorizan las tareas de cuidado por encima de otras actividades del hogar. Este mismo estudio pone de manifiesto que, las dos estrategias de conciliación más comunes en las madres monoparentales que trabajan fuera de casa son reorganizar su tiempo y convivir con otros familiares que puedan ayudarlas.

Eje 3: El tercer eje es la salud, donde se identifican problemas emocionales y de ajuste psicológico a la nueva realidad familiar. Estos están influenciados por la sobrecarga de responsabilidades que debe asumir la madre como único progenitor. De hecho, en las jefas de familias monoparentales, las triples jornadas de trabajo se acentúan, al tener que compaginar los cuidados y atenciones que requieren sus hijos con su jornada laboral y el trabajo doméstico. En estas familias es necesaria la intervención psicosocial, para facilitar el ajuste emocional a la nueva situación y el desarrollo de estrategias personales de afrontamiento.

Todas estas necesidades nos llevan a afirmar que las familias monoparentales en España son el tipo de familia que mayor riesgo de pobreza y exclusión social tienen (Santibáñez, Flores y Martín, 2018). De hecho, el Índice Sintético de Exclusión Social que elabora la Fundación FOESSA es más elevado para estas familias que para el resto. Se sitúa en 2,7 puntos, frente al 1,3 que se obtiene para el conjunto de hogares en los que la mujer es la sustentadora principal, y el 1,2 que alcanzan aquellos en los que el sustentador principal es un hombre (Fundación FOESSA, 2019). 
Fernández-Martínez y Avilés-Hernández

Según los últimos datos de la Encuesta de Condiciones de Vida, en 2018, el 50\% de los hogares monoparentales españoles con hijos menores de 18 años se encontraban en riesgo de pobreza y/o exclusión social (indicador AROPE). Este porcentaje era muy superior al 26,1\% que se obtenía de media para todos los hogares, o al 25,8\% de los hogares biparentales con niños dependientes. Esto tiene numerosas implicaciones para la infancia, que han sido constatadas por otros estudios (European Union, 2018; HernándezMonleón y Simó-Noguera, 2015; Marí-Klose, Marí-Klose, Vaquera y Cunningham, 2010).

El principal apoyo con el que cuentan para superar sus dificultades y resolver sus problemas es la familia. En términos de Meil (2002), es la "economía solidaria familiar" quien cubre las necesidades de los núcleos monoparentales y evita graves situaciones de precariedad en la infancia. El mayor riesgo de pobreza infantil que padecen los núcleos monoparentales de origen extranjero, señalado por Fundació Caixa Catalunya-Obra Social (2009), puede explicarse por la ausencia o inconsistencia del apoyo familiar.

Es importante indicar que la ayuda familiar está claramente feminizada. Destaca, en especial, la figura de la abuela, como cuidadora de los nietos mientras su hija trabaja. Ellas constituyen el principal recurso de conciliación con el que cuentan las madres solas (Fernández y Tobío, 1998; Morgado et al., 2003). La ayuda de los familiares es regular, se presta tanto a nivel económico y en especie, como a nivel emocional. También se da en cuestiones relativas al cuidado de los menores. Los análisis realizados por Malgesini (2018) indican que, 91\% de los hogares monoparentales de España considera que pueden solicitar ayuda tanto material como no material a familiares, amistades o conocidos. Este porcentaje es ligeramente superior al que se obtiene que para el conjunto de hogares. Esto indicaría, en palabras de Malgesini, que los hogares monoparentales españoles estiman poseer niveles de apoyo informal muy elevados.

En lo referente al apoyo institucional, las ayudas ofrecidas por los diferentes sistemas de protección social tienen un carácter puntual. Además, son insuficientes e ineficaces en la lucha contra la pobreza infantil (European Union, 2018; Meil, 2006). Ejemplo de las deficitarias medidas son las prestaciones económicas asistenciales de los diferentes sistemas de protección. Estas suponen unos ingresos por debajo del umbral de pobreza, lo que dificulta la cobertura de las necesidades básicas. La red de apoyo familiar es quien está dando la principal cobertura y atención ante las adversidades vitales. En muchos casos, la colaboración de la familia es imprescindible para evitar situaciones de pobreza y exclusión. De hecho, Flaquer (2000) señala que en España se ha fomentado el familismo, entendido como una contribución desmesurada de la familia a la protección social, en relación a otras agencias proveedoras de bienestar como el Estado y, por ende, los sistemas de protección social. 
Fernández-Martínez y Avilés-Hernández

Ante esto, se hace necesario que las instituciones públicas desarrollen políticas que garanticen la modificación de las circunstancias que conducen a estos grupos en particular, y a las familias en general, a situaciones de pobreza y exclusión social. Deben asumir su corresponsabilidad en la atención y cuidado de la infancia más vulnerable. Cantó y Ayala (2014) señalan que, el impacto social de la pobreza infantil a medio y largo plazo, requiere el desarrollo adecuado de políticas públicas a favor de la infancia para asegurar en el futuro niveles suficientes de bienestar social. Para ello, es prioritario el diseño de políticas públicas nacionales orientadas a la reducción de la pobreza infantil. Como señala la Unión Europea, combatir la pobreza infantil es imprescindible para preservar los derechos fundamentales del menor (European Union, 2018). EspingAndersen (2001) ya apuntaba que era necesaria una nueva política de familia en España, entendida como inversión de futuro y fundamentada en tres principios: prevenir la pobreza infantil, promover el empleo de las madres, y hacer compatibles el trabajo profesional y la formación de la familia.

Atendiendo a estos aspectos, se realizan las siguientes propuestas:

1. Creación de un Programa de Atención Integral, con carácter nacional, para familias monoparentales, donde se intervenga a todos los niveles: individual, familiar y grupal. La gestión del programa se haría de forma coordinada por un equipo multidisciplinar. Estaría integrado por trabajadores sociales, educadores, psicólogos, asesores jurídicos y orientadores laborales. El programa incluiría ayudas de distinta naturaleza: económicas, laborales, de vivienda, jurídicas, psicológicas, de formación, etc. Estas se intensificarían cuando se tratase de madres solas con niños menores de cinco años.

2. Desarrollo de ayudas económicas dirigidas a cubrir las necesidades básicas de los núcleos monoparentales con jefatura femenina que demuestren estar en situación o riesgo de pobreza y/o exclusión social.

3. Poner en marcha medidas laborales que favorezcan la inserción laboral de estas madres solas. Algunas serían la formación, jornadas laborales flexibles, mejoras fiscales para las empresas que las contraten, etc. Desarrollo de servicios de conciliación con amplios horarios, como guarderías, centros de educación infantil, ludotecas, etc., en los que se priorice el acceso de estas familias.

4. Normalizar los requisitos de acceso a las ayudas y prestaciones, y agilizar el tiempo de tramitación. Establecimiento de la Monoparentalidad como criterio de acción positiva en el acceso a recursos y servicios públicos.

5. Protección fundamental de los menores que pertenecen a estas familias, con ayudas y servicios específicos de acceso a la educación, salud, comedor, etc.

6. Agilizar los procesos judiciales de custodia y reclamación del pago de la pensión de alimentos al progenitor no custodio. 
Fernández-Martínez y Avilés-Hernández

7. Incorporación de la metodología de acompañamiento social en el proceso de intervención y relación de ayuda.

8. Integración de la metodología de trabajo en red en la intervención entre los diferentes servicios y sistemas de protección participantes.

9. Creación de grupos de facilitación y autoayuda, dirigidos al fomento de redes de apoyo informal, desarrollo de habilidades y estrategias de afrontamiento, aumento de la formación y empoderamiento de los miembros del grupo familiar.

\section{Referencias bibliográficas}

Almeda, E., Batalla, E., Camps, C., Collado, A., Di Nella, D., y Obiol, S. (Julio, 2010). Responsabilidad parental y monoparentalidad: análisis sociojurídico. En X Congreso Español de Sociología, FES, Pamplona, España.

Ajenjo, M., y García, N. (2019). La distribución del tiempo en los hogares monoparentales de madre ocupada. Vivir con otros como estrategia de conciliación. Revista Internacional de Sociología, 77(3), 1-16.

Avilés, M. (2013). Origen del concepto de monoparentalidad. Un ejercicio de contextualización sociohistórica. Papers, 98(2), 263-285.

Avilés, M. (2015). ¿Qué es la monoparentalidad? Una revisión crítica de su conceptualización en materia de Política Social. Cuadernos de Trabajo Social, 28(2), 211223.

Avilés, M. (2018). Gestión de conflictos en familias monoparentales. En A. Sánchez y P. López (Coords.), La solución alternativa de conflictos en los nuevos modelos de familia (pp. 249-272). Navarra, España: Editorial Aranzadi.

Barrón, S. (2002). Familias monoparentales: un ejercicio de clarificación conceptual y sociológica. Revista del Ministerio de Trabajo y Asuntos Sociales, (40), 13-29.

Cantó, O., y Ayala, L. (2014). Políticas Públicas para reducir la pobreza infantil en España: análisis de impacto. Barcelona, España: Editorial Unicef Comité Español.

Corral, E. (2008). La familia monoparental y el interés del menor. Actualidad Civil, (22), A2.

Domínguez, C., González, D., Navarrete, D., \& Zicavo, N. (2019). Parentification in singleparentfamilies. Ciencias Psicológicas, 13(2), 346-355.

Esping-Andersen, G. (22 de noviembre de 2001). La necesidad de una nueva política de familia. El País. Recuperado de https:/ / elpais.com/diario/2001/11/22/opinion/1006383607_850215.html.

European Union. (2018). Combating child poverty: an issue of fundamental rights. Luxembourg: Publications Office of the European Union.

Fernández, J.A., y Tobío, C. (1998). Las familias monoparentales en España. Revista Española de Investigaciones Sociológicas, 83(4), 51-85.

Flaquer, L. (2000). Las politicas familiares en una perspectiva comparada. Barcelona, España: Fundación La Caixa. 
Fernández-Martínez y Avilés-Hernández

Flaquer, L. (2004). Monoparentalidad. Arbor, 178(702), 345-376.

Flaquer, L., Almeda, E., y Navarro, L. (2006). Monoparentalidad e Infancia. Barcelona, España: Fundación La Caixa.

Fundació Caixa Catalunya-Obra Social (Ed.). (2009). Informe de la Inclusión Social en España. Barcelona, España: Fundación Caixa Catalunya. Recuperado de https://sid.usal.es/idocs/F8/FDO22112/informe_incl08.pdf.

Fundación FOESSA. (2019). VIII Informe sobre exclusión y desarrollo social en España. Madrid, España: Cáritas Española Editores. Recuperado de https://caritasweb.s3.amazonaws.com/main-files/uploads/sites/16/2019/05/Informe-FOESSA2019-completo.pdf.

Hernández-Monleón, A., y Simó-Noguera, C. (2015). La precariedad en los hogares con niños: diferencias entre las madres de hogares biparentales y hogares monomarentales en el período 1995-2010. Oñati Socio-legal Series, 5(4), 1133-1151.

Iglesias de Ussel, J. (1988). La Situación de la Familia en España y los Nuevos Modelos Familiares. En J. Iglesias de Ussel (Ed.), Las Familias Monoparentales (pp. 23-40). Madrid, España: Instituto de la Mujer, Ministerio de Asuntos Sociales.

Iglesias de Ussel, J. (1998). La familia y el cambio político en España. Madrid, España: Editorial Tecnos.

Instituto Nacional de Estadística de España-INE. (2020). Encuesta Continua de Hogares. Madrid, España: INE.

Llano, J.C. (2019). El estado de la pobreza. Seguimiento del indicador de pobreza y exclusión social en España2008-2018. Madrid, España: EAPN - European Anti Poverty Network.

López-Mero, P., y Pibaque-Tigua, M. (2018). Familias monoparentales y el desarrollo social en los adolescentes. Revista Dominio de las Ciencias, 4(3), 152-162.

Malgesini, G. (2018). Estudio sobre las Familias Monoparentales perceptoras de Rentas mínimas. Madrid, España: EAPN - European Anti Poverty Network.

Marí-Klose, P., Marí-Klose, M., Vaquera, E., y Cunningham, S. (2010). Infancia y futuro. Nuevas realidades, nuevos retos. Barcelona, España: Fundación La Caixa. Recuperado de https://www.observatoriodelainfancia.es/ficherosoia/documentos/2980_d_Infancia_Futuro.pdf.

Meil, G. (2002). La otra cara del desafío demográfico a la protección social: Los desafíos derivados del cambio familiar. Revista del Ministerio de Trabajo y Asuntos Sociales, (36), 95-115.

Meil, G. (2006). Padres e hijos en la España actual. Barcelona, España: Fundación La Caixa.

Méndez, T. (2015). Redes de apoyo social en familias monoparentales y nucleares: un análisis de los efectos en la crianza y la marentalidad (Tesis Doctoral). Universidad de Oviedo. Oviedo, España.

Ministerio de Sanidad, Servicios Sociales e Igualdad. (2013). Catálogo de referencia de servicios sociales. Madrid, España: Ministerio de Sanidad, Servicios Sociales e Igualdad. Recuperado de https://www.mscbs.gob.es/ssi/familiasInfancia/ServiciosSociales/docs/CatalogoS erviciosSociales.pdf. 
Fernández-Martínez y Avilés-Hernández

Ministerio de Trabajo y Asuntos Sociales. (2007). El sistema público de servicios sociales: plan concertado de prestaciones básicas de servicios sociales en corporaciones locales, 2005-2006. Madrid, España: Ministerio de Trabajo y Asuntos Sociales.

Morgado, B., González, M.M., y Jiménez, I. (2003). Familias monomarentales: problemas, necesidades y recursos. Portularia: Revista de Trabajo Social, 3, 137-160.

ONU Mujeres. (2019). El progreso de las mujeres en el mundo 2019-2020. Familias en un mundo cambiante. Recuperado de https://www.unwomen.org/es/digital-library/progressof-the-worlds-women.

Ramón, F. (2019). La monoparentalidad derivada de la violencia de género: análisis de la cuestión. Revista sobre la infancia y la adolescencia, (16), 14-28.

Richmond, M.E. (1995).El Caso social individual / El diagnóstico social (Textos seleccionados). Madrid, España: Talasa.

Rodríguez, C., y Luengo, T. (2003). Un análisis del concepto de familia monoparental a partir de una investigación sobre núcleos familiares monoparentales. Papers, 69,5982.

Rodríguez, C., y Luengo, T. (2011). Una lectura de la monoparentalidad desde la perspectiva de la posmodernización de la familia. En E, Almeda y D. Di Nella (Dirs.), Las Familias Monoparentales adebate (pp.55-84). Barcelona, España: Copalqui Editorial.

Ruiz, D. (2004). Nuevas formas familiares. Portularia: Revista de Trabajo Social, 4, 219-230.

Santibáñez, R., Flores, N., y Martín, A. (2018). Familia monomarental y riesgo de exclusión social. Iqual. Revista de Género e Igualdad, (1), 123-144.

Sastre, A. (2015). Más solas que nunca. La pobreza infantil en familias monomarentales. Madrid, España: Savethechildren.

Setién, M.L., y Arriola, M.J. (1997). Política Social y servicios Sociales. En C, Alemán y J. Garcés (Coords.), Política Social (pp. 323-353). Madrid, España: Mc Grau Hill.

Tobío, C. (2002).Conciliación o contradicción: cómo hacen las madres trabajadoras. Revista Española de Investigaciones Sociológicas, (97), 155-186. 


\section{OTROS ARTÍCULOS DE PROSPECTIVA No. 30 DE 2020}

\section{EDITORIAL}

Coherencia, integridad y vida cotidiana

Luz Mary Sánchez-Rengifo

\section{ARTÍCULOS}

Trabajo Social y medios de comunicación: perspectivas y posibilidades de encuentro Social

Mercedes Muriel-Saiz

Maribel Martín-Estalayo

Seguridad, afectos y familias. Obstáculos en el proceso de reintegración de personas desmovilizadas de grupos

armados en Santander, Colombia

Jakeline Vargas-Parra

Ángela María Díaz-Pérez

Priscyll Anctil-Avoine

Reflexividad sobre la intervención profesional en duelo con población afectada por el conflicto armado en Colombia

María Cénide Escobar-Serrano

Maritza Charry-Higuera

Natalia Ramírez-Moncada

Ser mujer indígena, náhuatl, casada, migrante, sin trabajo remunerado: una realidad en los albergues jornaleros agrícolas en Colima, México

Nancy Elizabeth Molina-Rodríguez

Tipos y manifestaciones de la violencia de género: una visibilización a partir de relatos de mujeres víctimas en Soacha, Colombia

Diana Carolina Tibaná-Ríos

Diana Alejandra Arciniegas-Ramírez

Ingrid Julieth Delgado-Hernández

Análisis de necesidades en familias monoparentales con jefatura femenina usuarias de servicios sociales de atención primaria en España

Celia María Fernández-Martínez

Manuela Avilés-Hernández

Experiencias de intervención de trabajadoras sociales con trabajadores sexuales masculinos en Bogotá, Colombia Johan Arturo Barrera-Castellanos
Condiciones laborales de trabajadores sociales en hospitales públicos en la provincia de Mendoza,

Argentina

Cecilia Amalia Molina

Yanina Noemi Roslan-Angeloni

Analía Graciela Correa

Viviana Elena Varela

Gubernamentalidad neoliberal: miradas desde las intervenciones del Trabajo Social en el Gran La Plata, Argentina

Paula Mara Danel

Marcela Claudia Velurtas

Agustina María Favero-Avico

Educación superior en Trabajo Social en Chile y formación para la intervención en situación de calle. Desafios desde la evaluación que interventores hacen de sus procesos de práctica pre-profesional

Carlos Alejandro Andrade-Guzmán

Ignacio Andrés Eissmann-Araya

Educación en Derechos Humanos para el Trabajo Social en Chile: una mirada desde los estándares

internacionales

Lury Soledad Reyes-Pérez

Vivianne Soledad Hasse-Riquelme

Luis Marcelo Silva-Burgos

Arriesgar y preservar la vida: derechos humanos, conflicto sociopolítico armado y Trabajo Social en Colombia

Cristian Sebastián Castaño-Orozco

Ricardo Patiño-Martínez

\section{IN MEMORIAM}

Cristina Bautista Taquinás. Mujer indígena Nasa, Trabajadora Social, lideresa del norte del Cauca, Colombia

Alba Nubia Rodríguez-Pizarro

Lady Johanna Betancourt-Maldonado
ARTISTA INVITADO
MALA JUNTA KLAN
Alejandra Gutiérrez-Cárdenas

\section{PROSPECTIVA}

